ISSN electrónico: 2172-9077

DOI: https://doi.org/10.14201/fjc202021255257

\title{
EL ÚLTIMO ESCRITO DEL FILÓSOFO LÍQUIDO
}

\section{The Last Writing of the Liquid Philosopher}

Dra. Martha Elena CUEVAS GÓMEZ

Profesora-investigadora Universidad Juárez Autónoma de Tabasco, México

martha.cuevas@ujat.mx

(iD) https://orcid.org/0000-0002-3760-4356

Fecha de recepción de la reseña: 06/06/2020

Fecha de aceptación definitiva: 16/12/2020

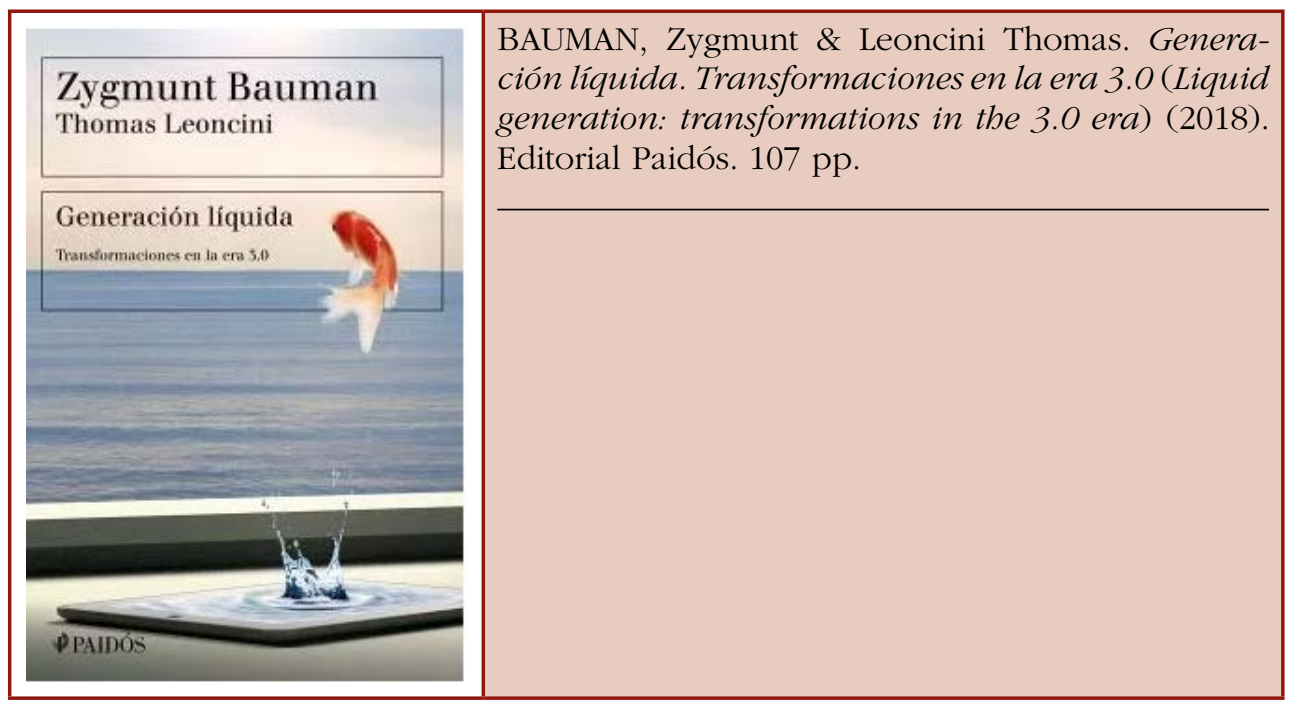

\section{Introducción}

¿Cómo influye la estética en el cuerpo? ¿Por qué nos importa más la comunidad que la identidad? ¿Qué relación existe entre el amor y las 24 horas siguientes para las nuevas generaciones? En la era de las tecnologías, dentro de una sociedad que vive más online que offline, cualquier conducta social se transforma, crea y genera conductas que lejos 
de la individualidad se masifican para encontrarnos finalmente solos en medio de la realidad.

Generación líquida, transformaciones en la era 3.0 es la obra póstuma de Zygmunt Bauman que recapitula las conversaciones con Thomas Leoncini, sobre temáticas que sociológicamente inundan a la nueva sociedad del conocimiento, interconectada como una condición facilitadora fundamental para la supervivencia social y pública.

El tema de la sociedad líquida abordado por Bauman en otras obras como «la ambivalencia de la modernidad" (2002), "la ceguera moral (2015) y "la maldad líquida» (2016), retrata en esta obra una forma más detallada de temas relevantes en el tejido social que establece pautas de conducta colectiva en función de actitudes, normas o esquemas que rompen las normalidades de las esferas públicas para mantener en gran parte de la visión, una actitud individual que encaja, se adapta y armoniza obligada por las circunstancias.

El concentrado de correos que son enviados con planteamientos específicos de Leoncini y dilucidadas por Bauman, se desarrollan a partir de una reflexión de entornos pasados y presentes, comparativos que en la actualidad revelan una atención prioritaria por las identidades virtuales, falsificables e impunes en muchos casos.

Las particularidades de la existencia virtual a su vez; favorece la individualidad cómoda, donde a diferencia de la cotidianeidad real, se puede excluir e incluir, bloquear o aceptar, desear o desdeñar a personas de una pestaña a otra, sin permanecer "anclado" a ningún tema, pero en función de los intereses liberales; es decir la convivencia contemporánea en el mismo lugar.

La obra editada en 2018 se divide en tres partes; donde se abordan los temas de tatuajes, cirugías pláticas, hípsters, acoso escolar y la decadencia de los tabúes en la era del comercio electrónico sentimental; con una particularidad especial; la forma de vivir de los nativos líquidos que, -en palabras de Leoncini- no tienen más que los medios.

Aunque la individualidad juega un papel fundamental en el desarrollo de los entornos digitales, establecer el papel que juegan las identidades revela también que la atención social está puesta en una colectividad exigente que no se detiene en establecer tendencias, modas o comportamientos para marcar a su vez la exclusividad de la pertenencia a un grupo.

Es esta situación de pertenencia, la que marca también los cuerpos como parte de elementos que nos combinan o no, con las personalidades pero que -a diferencia de otras generaciones- ya no representan luchas o protestas del ámbito social, porque han sido desplazadas por la necesidad de encajar al menos por la imagen pública.

Es este tema de la proyección individual hábilmente desarrollada lo que aborda la construcción de la propia destrucción del cuerpo original, sustituido por las cirugías plásticas, como un elemento de básico para ser lo que idealmente se considera bello en el mundo líquido.

Bauman también apunta esta necesidad de exponer públicamente la realización de una cirugía plástica, como un elemento de superioridad social, dentro del entorno capitalista. "Yo tengo para hacerlo, entonces lo hago" y su exposición pública que en un momento pudo ser oculta, ahora se convierte en un emblema de poder, para situar a los beneficiaos de la cirugía plástica por encima de los que no podrán hacerla. Es decir; el lenguaje utilizado en la connotación amplia de superioridad

El manejo de emociones es parte fundamental del segundo episodio de esta obra, que revela también estas modificaciones de acoso escolar que se vivían en otros 
tiempos y que ahora ante nuevas formas de ser nombradas parecieran ser más agresivas o tener más importancia que en el pasado. No obstante; dilucidar el tema, también refiere que los acosados, víctimas de agresiones ahora a través de la virtualidad actúan de forma distinta según los sexos; mientras los hombres recurren a la violencia, las mujeres a la indiferencia y a la exclusión.

Los resultados del acoso en la era actual se reflejan también en la forma en la que se adoptan medidas que convengan a los interesados, que en la mayoría de las veces busca la aprobación de sus propios agresores como un medio de aceptación social.

Los diálogos que intercalan los temas a profundidad también refieren las condiciones del amor, en el capítulo de las transformaciones sexuales y amorosas, un tema abordado hace más de una década por Giles Lipovetsky en su libro De la ligereza, pero que aporta elementos de la interminable discusión entre el amor y el deseo. Las consideraciones ahora, sin embargo, están marcadas por las formas de existencia de ambos sentimientos, las pertenencias y las oportunidades, dominio, poder, fusión y desencanto del amor virtual son elementos necesarios para su análisis que Leoncini plantea como el arma hipermoderna para sustituir al amor romántico casi extinto.

La reducción de la esfera privaada dentro del amor no ha sido suficiente para concebir la situación sentimental de una pareja, ligada por los múltiples accesorios tecnológicos que se convirtieron solamente en un escaparate de la condición humana sino también en la modificación psicológica de nuestros prototipos sinestésicos.

Implicando la necesidad de libertad en sacrificio de la seguridad, el nuevo amor no se encuentra sujeto a nada, marca su decisión de integración solamente a través de vivir sin compromisos, independientemente del género. La libertad entonces es el único modelo de ese amor eterno que dura 24 horas.

El análisis necesario para la comprensión de los fenómenos comunicacionales actuales otorga una visión novedosa de las conductas en un antes y un después en los ámbitos generacionales, que integra un segmento dedicado bajo el tema de la última lección, escrita por Leoncini y enfocada a la muerte de Bauman en 2017, mientras escribían este libro.

Esta flexibilidad que se modifica rápidamente en cada uno de los aspectos de la vida pública y la esfera privada marca una aportación a las líneas de comunicación necesaria para los análisis de consumo, imagen pública y lenguaje, con lo que se puede retratar y entender a la nueva sociedad, sus ritos, usos y adaptaciones del conocimiento de una generación pasada.

La crítica, sin embargo, se implicaría por algunos temas que dejan al lector con las intenciones de seguir buscando, leyendo, explicando y que hace la obra ligera pero también ambiciosa, y es esto último es lo que plantea nuevas preguntas de la condición humana.

\section{Bibliografía}

Bauman, Z., \& Leoncini, T. (2018). Generación líquida. Transformaciones en la era 3.0 (1st ed., p. 107). México: Paidós. 
